VARELLA, Marcelo D.; DEMATTÉ, Flávio R.. Limites e possibilidades de melhoria dos programas de whistleblowers para o combate à corrupção no brasil. Revista Eletrônica Direito e Política, Programa de Pós-Graduação Stricto Sensu em Ciência Jurídica da UNIVALI, Itajaí, v.15, n.2, 20 quadrimestre de 2020. Disponível em: www.univali.br/direitoepolitica - ISSN 1980-7791

\title{
LIMITES E POSSIBILIDADES DE MELHORIA DOS PROGRAMAS DE WHISTLEBLOWERS PARA O COMBATE À CORRUPÇÃO NO BRASIL
}

\author{
LIMITS AND POSSIBILITIES FOR IMPROVING WHISTLEBLOWERS 'PROGRAMS TO
}

COMBAT CORRUPTION IN BRAZIL

\author{
Marcelo D. Varella ${ }^{1}$ \\ Flávio R. Dematté
}

\section{RESUMO}

Este artigo faz uma análise dos programas de whistleblowers, partindo da sua origem no direito norte-americano, Europeu até a sua consolidação no cenário internacional. Parte-se da premissa que o programa de proteção de denunciantes é essencial para o avanço do combate a corrupção no Brasil. A metodologia consiste em examinar os elementos normativos e comportamentais que configuram a estrutura e a efetividade destes programas, explicar como o tema se desenvolveu em vários países no mundo. Em seguida, mostrar quais os principais pontos que foram objeto de aperfeiçoamento nos demais países e discutidos no tribunais internacionais. Depois, como o tema foi construído no Brasil. Por fim, a luz das experiências internacionais e das discussões na ENCCLA, propor melhorias à legislação brasileira. Conclui-se que o o programa de proteção de testemunhas precisa ser aperfeiçoado, em virtude das experiências encontradas na sua implementação e propõe tais alterações.

PALAVRAS-CHAVE: Denunciantes de boa-fé; Corrupção; Estímulos comportamentais.

\section{ABSTRACT}

This paper analyzes the whistleblower programs, starting from their origin in North American and European law until their consolidation in the international scenario. It is based on the premise that the whistleblower protection program is essential for advancing the fight against corruption in everywhere, and mostly in Brazil. The methodology consists of examining the normative and behavioral elements that configure the structure and effectiveness of these programs, explaining how the theme has developed in several countries in the world. Then, show the main points that have been improved in other countries and discussed in international courts. Then, the paper presentes the Brazilian legal. Finally, in the light of international experiences and discussions at ENCCLA, propose improvements to Brazilian

\footnotetext{
1 Doutor em Direito pela Universidade de Paris. Livre-Docente pela USP. Pesquisador do CNPq. Coordenador do Programa de Mestrado e Doutorado em Direito do UNICEUB. E-mail: marcelodvarella@gmail.com.

2 Mestre em Direito e Auditor Federal de Finanças e Controle da Controladoria-Geral da União. E-mail: flaviodematte@gmail.com.
} 
VARELLA, Marcelo D.; DEMATTÉ, Flávio R.. Limites e possibilidades de melhoria dos programas de whistleblowers para o combate à corrupção no brasil. Revista Eletrônica Direito e Política, Programa de Pós-Graduação Stricto Sensu em Ciência Jurídica da UNIVALI, Itajaí, v.15, n.2, 20 quadrimestre de 2020. Disponível em: www.univali.br/direitoepolitica - ISSN 1980-7791

legislation. It is concluded that the witness protection program needs to be improved, due to the experiences found in its implementation and proposes such changes.

KEYWORDS: Whistleblowers; Corruption; Nudges.

\section{INTRODUÇÃO}

Originado no direito norte-americano e atualmente previsto em diversos atos normativos estrangeiros e internacionais, o termo whistleblower (whistle $=$ apito + blower $=$ soprador) se refere à pessoa que espontaneamente e de boa-fé reporta um ato infracional relevante de que tem informação àqueles que têm competência para conhecer e apurar tal irregularidade ${ }^{3}$. No Brasil, adota-se a expressão sinônima "reportante de boa-fé". Os fatos a serem relatados vão desde violações a normas corporativas internas, passando por fraudes no mercado de capitais ou até mesmo atos de corrupção e de lesão ao erário. Criar incentivos adequados para que as pessoas decidam denunciar ilícitos diante de potenciais mal feitos é o principal desafio que se coloca para a regulação de programas de whistleblowers, podendo a economia comportamental oferecer importantes insights para a estimular o alerta sobre crimes mediante uma arquitetura de escolhas que propicie a decisão de "soprar o apito", sobretudo frente a fatos relacionados com corrupção.

Por ser praticada em círculos fechados, por deixar rastros de difícil identificação e por não vitimar um indivíduo específico, a detecção e a dissuasão da corrupção desafiam os instrumentos apuratórios convencionalmente utilizados pelo Estado, o que torna o recebimento de informações obtidas próximas ao âmbito de cometimento do delito um elemento-chave para o esclarecimento dos fatos. Nesse contexto, os programas de estímulos a denúncias de boa-fé emergem como importantes ferramentas para canalização de informações mais qualificadas acerca de potenciais esquemas de corrupção às autoridades competentes para apuração. Mas esse fim só será alcançado com êxito se tais programas forem estruturados de modo a conceberem uma rede de estímulos que encoraje as pessoas a adotarem uma postura de reportar o que sabem

\footnotetext{
${ }^{3}$ Em razão da ampla difusão e aceitação dos termos whistleblower e whistleblowing no meio acadêmico e jurídico, o presente texto manterá o anglicismo ao invés de utilizar a tradução literal para o português ("soprador de apito" e "o ato de soprar o apito", respectivamente). Por vezes, será empregado o termo "reportante" como sinônimo de whistleblower, mas sempre no contexto da definição ora apresentada.
} 
VARELLA, Marcelo D.; DEMATTÉ, Flávio R.. Limites e possibilidades de melhoria dos programas de whistleblowers para o combate à corrupção no brasil. Revista Eletrônica Direito e Política, Programa de Pós-Graduação Stricto Sensu em Ciência Jurídica da UNIVALI, Itajaí, v.15, n.2, 20 quadrimestre de 2020. Disponível em: www.univali.br/direitoepolitica - ISSN 1980-7791

e, ao mesmo tempo, um aparato de medidas que as protejam contra eventuais retaliações que possam sofrer em decorrência de terem reportado.

O tema ganha especial relevância para o sistema anticorrupção brasileiro por três motivos. Em primeiro lugar, porque os programas de estímulos ainda não foram regulados por nenhum ato normativo pátrio, embora a matéria já seja objeto de alguns projetos de lei em curso no Congresso Nacional. Em segundo lugar, porque a figura do denunciante ou reportante de boa-fé possui características próprias, não se confundindo com a de outras pessoas que também colaboram com o fornecimento de informações sobre atos ilícitos, tais como os delatores, as testemunhas ou os reportantes em geral. $E$, em terceiro lugar, porque os programas integrariam e complementariam o conjunto de novos mecanismos de que o Estado tem se valido para tomar conhecimento e apurar fatos relacionados a corrução, a exemplo das colaborações premiadas e dos acordos de leniência, os quais têm possibilitado às autoridades competentes o acesso a informações que não teriam sido obtidas sem a participação de insiders. Em suma, está-se diante de vácuo regulatório no Brasil a respeito de instituto que já se encontra difundido em diversos países e que possui grande potencial para contribuir com o aperfeiçoamento do combate à corrupção, cenário este favorável a que os aportes teóricos da economia comportamental sejam considerados juntamente com 0 direito em prol de uma regulação comportamentalmente orientada dos programas de estímulos a denúncias de boa-fé ou whistleblowing.

A fim de compreender como as contribuições da economia comportamental podem ser incorporadas à regulação de programas de whistleblowers anticorrupção, é necessário primeiramente examinar a origem e a evolução do instituto na legislação norteamericana e a sua posterior disseminação a outros países, a qual encontrou amparo nos principais tratados que versam especificamente sobre combate à corrupção, bem como identificar as principais diretrizes e elementos estruturantes que precisam estar normativamente presentes em um programa de whistleblower. Na sequência e após a apresentação da base conceitual da economia comportamental, serão propostas algumas medidas baseadas em intervenções informadas pelo comportamento, a exemplo de nudges, de como a exploração das heurísticas e dos vieses cognitivos pelo regulador - seja ele privado ou público - podem conduzir ao desenvolvimento 
VARELLA, Marcelo D.; DEMATTÉ, Flávio R.. Limites e possibilidades de melhoria dos programas de whistleblowers para o combate à corrupção no brasil. Revista Eletrônica Direito e Política, Programa de Pós-Graduação Stricto Sensu em Ciência Jurídica da UNIVALI, Itajaí, v.15, n.2, 20 quadrimestre de 2020. Disponível em: www.univali.br/direitoepolitica - ISSN 1980-7791

comportamentalmente orientado de programas de estímulos a denúncias de boa-fé. Por fim, será feita uma análise crítica dos projetos de lei em curso no Congresso Nacional e dos atos normativos em vigor que visam regular a prática no Brasil, com o objetivo de se identificar se tais propostas favorecem ou não um modelo de regulação comportamentalmente orientada acerca da matéria.

\section{A EXPANSÃo dO DENÚNCIA DE BOA-FÉ COMO INSTRUMENTO ANTICORRUPÇÃO NO DIREITO ESTRANGEIRO E INTERNACIONAL}

Tanto no seu país de origem (os Estados Unidos da América), por conta de uma constante evolução legislativa, quanto em diversos outros países, por força de alguns tratados específicos, o instituto do whistleblower tem sido cada vez mais utilizado pelo setor privado e pelo Estado como instrumento de detecção de atos ilícitos relacionados a corrupção, principalmente o pagamento de suborno a agentes públicos.

A ressaca política e moral que se abateu sobre a sociedade norte-americana em razão dos fatos relacionados ao Caso Watergate em 1972 foi seguida por uma ampla reflexão crítica quanto ao funcionamento da Administração Pública e do sistema político dos EUA e, em especial, no tocante aos limites das relações entre os setores público e privado. Como resultado, as instituições estatais, sobretudo o Poder Legislativo, foram pressionadas a adotar medidas que de alguma forma contribuíssem para o revigoramento da confiança da população na capacidade e na qualidade do aparato político-partidário em administrar a coisa pública, os interesses da coletividade e o próprio país.

Um dos frutos desse movimento foi à aprovação do Civil Service Reform Act (CSRA), em $1978^{4}$, que previu, dentre as medidas de reforma do serviço público prestado por civis nos EUA, dispositivos que expressamente protegiam funcionários públicos - no caso, federais - contra perseguições partidárias e retaliações em razão de denúncias que viessem a fazer quanto a atos ilícitos, como, por exemplo, o desperdício de recursos públicos. A referida lei vigorou até 1989, quando foi substituída pelo

\footnotetext{
${ }^{4} \mathrm{O}$ advento do Foreign Corrupt Practices Act (FCPA), de 1977, o primeiro instrumento legal do mundo a reprimir o suborno de agentes públicos estrangeiros, também está inserido nesse momento da história política dos EUA.
} 
VARELLA, Marcelo D.; DEMATTÉ, Flávio R.. Limites e possibilidades de melhoria dos programas de whistleblowers para o combate à corrupção no brasil. Revista Eletrônica Direito e Política, Programa de Pós-Graduação Stricto Sensu em Ciência Jurídica da UNIVALI, Itajaí, v.15, n.2, 20 quadrimestre de 2020. Disponível em: www.univali.br/direitoepolitica - ISSN 1980-7791

Whistleblower Protection Act (WPA), que passou a tratar especificamente do whistleblowing no setor público federal, ampliou o sistema de garantias conferidas aos reportantes e criou uma agência dedicada a promover o cumprimento de tais medidas protetivas: o Office of Special Counsel (OSC) ${ }^{5}$. Mais recentemente, em 2012, o WPA sofreu uma série de aprimoramentos legais, visando, sobretudo, ampliar, para todas as onze Cortes de Apelação do Circuito Federal, a circunscrição jurisdicional responsável por apreciar a proteção dos whistleblowers ${ }^{6}$.

Sem versar especificamente sobre funcionários públicos, duas importantes leis setoriais federais norte-americanas que estipulam importantes cláusulas protetivas a whistleblowers são a Sarbanes-Oxley Act (SOX), de 2002, aprovada em resposta ao escândalo financeiro envolvendo a Enron, e o Dodd-Frank Act, de 2010, editado com o objetivo de contribuir para a restauração da estabilidade econômica dos EUA, abalada pela crise financeira das hipotecas subprimes em 2008. Ambas as leis se voltam à prevenção de fraudes corporativas, cujos efeitos nocivos para o interesse público e para a economia popular se mostraram patentes no contexto histórico que motivou a publicação das referidas normas, e tratam os whistleblowers como agentes fundamentais para a promoção da transparência e da accountability do sistema financeiro e do ambiente corporativo ${ }^{7}$. Como estas duas leis estão associadas ao Securities Exchange Act, de 1934, que regula o mercado mobiliário norte-americano, alterando-a em diversos pontos, todas as empresas estrangeiras que possuem ações emitidas nas bolsas de valores dos EUA estão sujeitas às disposições que determinam a proteção de whistleblowers.

\footnotetext{
${ }^{5}$ Nos termos da Seção 2, alínea "a", item 2, do WPA, o Congresso considera a proteção de empregados que divulgam ilegalidades do Governo, desperdício e corrupção um passo essencial em direção a um serviço público mais efetivo.

${ }^{6}$ Segundo o relatório elaborado pelo Senado Norte-Americano (2012) para subsidiar o aperfeiçoamento do WPA, a revelação de fatos relacionados a segurança nacional, sobretudo no mundo "pós-11/09", deveria ser estimulada sem o temor de represálias e ameaças. Contudo, segundo os senadores, a interpretação estreita que vinha sendo dada pela Corte de Apelações dos Estados Unidos para o Circuito Federal - que até então detinha jurisdição exclusiva para casos relacionados ao WPA - quanto ao tipo de revelação que qualifica alguém a receber as medidas protetivas da lei não estava contribuindo para estimular o whistleblowing por parte de funcionários públicos federal.

7 Paralelamente à referida legislação federal, Vaughn (1999, p. 582) aponta que várias outras leis que protegem whistleblowers foram editadas pelos Estados norte-americanos, muitas delas voltadas para áreas específicas, como serviços de saúde, abuso de crianças e idosos, lares adotivos, emissões de veículos automotores, relações laborais e fraudes em seguros.
} 
VARELLA, Marcelo D.; DEMATTÉ, Flávio R.. Limites e possibilidades de melhoria dos programas de whistleblowers para o combate à corrupção no brasil. Revista Eletrônica Direito e Política, Programa de Pós-Graduação Stricto Sensu em Ciência Jurídica da UNIVALI, Itajaí, v.15, n.2, 20 quadrimestre de 2020. Disponível em: www.univali.br/direitoepolitica - ISSN 1980-7791

A consolidação do whistleblowing na legislação norte-americana como um importante instrumento de revelação de atos ilícitos atentatórios ao interesse público cumulada com a dispersão global do instituto por meio da sua internalização nas estruturas de governança corporativa das empresas estrangeiras que emitiam ações nos EUA contribuíram para que a proteção de reportantes chamasse a atenção de organismos internacionais. Banisar $(2011)^{8}$ observa que diversos instrumentos normativos internacionais - sobretudo aqueles referentes ao combate à corrupção - passaram a reconhecer a importância do whistleblowing e a incentivar os países a adotarem medidas que estimulassem o seu emprego e que protegessem os reportantes.

Na União Europeia, a obrigação de servidores públicos relatarem ilícitos que tenham conhecimento é bastante antiga. A partir dos anos 80, há a instituição da proteção de relatores que informam situações irregulares, especialmente em matéria de saúde pública e segurança do trabalho, seja em empresas públicas ou privadas. A partir dos anos 2000, diversas empresas de grande porte começaram a adotar dispositivos de alerta profissional em matéria contábil e financeira, sobretudo em função da legislação americana com efeitos extraterritoriais. O instituto se expande em 2007, na França e em outros países europeus, para temas como abusos sexuais de crianças e adultos vulneráveis e, enfim, em casos de combate à corrupção. A partir de 2013, há a ampliação da proteção e recompensa para danos ao meio ambiente e risco graves para saúde pública (Conseil d’Etat, 2016) ${ }^{9}$.

Para citar dois dos mais importantes diplomas internacionais anticorrupção assinados pelo Brasil, tanto a Convenção das Nações Unidas Contra a Corrupção (art. $33^{10}$ ), internalizada por meio do Decreto no 5.687, de 2006, como a Convenção Interamericana Contra a Corrupção (art. III, item $8^{11}$ ), internalizada por meio do

\footnotetext{
${ }^{8}$ BANISAR, David. Whistleblowing: international standards and developments. Disponível em: <ssrn.com/abstract=1753180 >. Acesso em: 20 de janeiro de 2018.

${ }^{9}$ CONSEIL d'ETAT. Le droit d'alerte: signaler, traiter protéger. Paris: La Documentation Française, 2016.

10 Art. 33. Cada Estado Parte considerará a possibilidade de incorporar em seu ordenamento jurídico interno medidas apropriadas para proporcionar proteção contra todo trato injusto às pessoas que denunciem ante as autoridades competentes, de boa-fé e com motivos razoáveis, quaisquer feitos relacionados com os delitos qualificados de acordo com a presente Convenção.

11 Para os fins estabelecidos no artigo II desta Convenção, os Estados Partes convêm em considerar a aplicabilidade de medidas, em seus próprios sistemas institucionais destinadas a criar, manter e fortalecer: (...) 8. Sistemas para proteger funcionários públicos e cidadãos particulares que denunciarem
} 
VARELLA, Marcelo D.; DEMATTÉ, Flávio R.. Limites e possibilidades de melhoria dos programas de whistleblowers para o combate à corrupção no brasil. Revista Eletrônica Direito e Política, Programa de Pós-Graduação Stricto Sensu em Ciência Jurídica da UNIVALI, Itajaí, v.15, n.2, 20 quadrimestre de 2020. Disponível em: www.univali.br/direitoepolitica - ISSN 1980-7791

Decreto no 4.410, de 2002, preveem expressamente que os Estados Partes devem desenvolver mecanismos de proteção a whistleblowers que denunciem atos de corrupção $^{12}$.

Embora a Convenção da OCDE sobre o Combate da Corrupção de Funcionários Públicos Estrangeiros em Transações Comerciais Internacionais ou simplesmente "Convenção sobre Suborno Transnacional" - internalizada por meio do Decreto no 3.678, de 2000 - não contemple disposição de idêntico teor, o grupo de trabalho da OCDE que monitora a implementação da referida Convenção (OECD Working Group on Bribery - WGB) examina em um item específico dos seus relatórios periódicos a existência e o funcionamento de medidas protetivas a whistleblowers no país avaliado, a exemplo do item 10.c do relatório da fase 3 do Brasil (OCDE) ${ }^{13}$.

Além do seu acolhimento em tratados anticorrupção, o whistleblowing também têm sido objeto de constante debates em fóruns internacionais como a Transparência Internacional e o G20, que, embora não possuam poder legiferante, exercem um importante papel de fomento à reflexão sobre os temas que aborda em seus estudos, cujas recomendações e diretrizes se apresentariam como formas de soft law. A primeira elaborou em 2013 uma lista de princípios a serem observados na elaboração de legislações sobre whistleblower, tomando por base algumas boas práticas desenvolvidas por países que já haviam disposto sobre o tema TRANSPARÊNCIA INTERNACIONAL ${ }^{14}$. O G20, por sua vez, produziu em 2012 um relatório de teor semelhante, comparando as medidas de whistleblowing implementadas pelos países que integram o grupo $\mathrm{G} 20^{15}$. As principais orientações legislativas apresentadas

de boa-fé atos de corrupção, inclusive a proteção de sua identidade, sem prejuízo da Constituição do Estado e dos princípios fundamentais de seu ordenamento jurídico interno.

12 Além destes dois tratados, Banisar (2011) menciona ainda o art. 9 da Convenção da Lei Civil Sobre Corrupção do Conselho da Europa, em vigor desde 2003, e o art. 5 da Convenção da União Africana sobre Corrupção, em vigor desde 2006.

${ }^{13}$ OCDE. Phase 3 Report on implementing the Anti-Bribery Convention in Brazil, 2014, pg. 63.. Disponível em: <www.oecd.org/daf/anti-bribery/Brazil-Phase-3-Report-EN.pdf>. Acesso em: 15 de dezembro de 2017.

14 TRANSPARÊNCIA INTERNACIONAL. International principles for whistleblower legislation, 2013. Disponível

em: <www.transparency.org/whatwedo/publication/international_principles_for_whistleblower_legislation>. Acesso em: 04 de novembro de 2017.

15 G20. Study on whistleblower protection frameworks: compendium of best practices and guiding principles for legislation, 2012. Disponível em: <www.oecd.org/g20/topics/anticorruption/48972967.pdf>. Acesso em: 06 de novembro de 2017. 
VARELLA, Marcelo D.; DEMATTÉ, Flávio R.. Limites e possibilidades de melhoria dos programas de whistleblowers para o combate à corrupção no brasil. Revista Eletrônica Direito e Política, Programa de Pós-Graduação Stricto Sensu em Ciência Jurídica da UNIVALI, Itajaí, v.15, n.2, 20 quadrimestre de 2020. Disponível em: www.univali.br/direitoepolitica - ISSN 1980-7791

nestes dois estudos serão examinadas no próximo tópico, onde se abordará a estrutura normativa de um programa de whistleblower.

No âmbito europeu, a Corte Europeia de Direitos Humanos considera a proteção do reportante de boa-fé como um direito relacionado à liberdade de expressão. O direito é garantido tanto no setor privado, como no setor público, sobretudo em casos em que há violação dos direitos humanos, compreendida de forma ampla. Considera-se que houve uma violação da liberdade de expressão dessa natureza quando: (a) o direito de denúncia é previsto em lei; (b) o que se reporta é legítimo, ou seja, ao menos há uma suspeita que merece ser investigada; (c) a publicidade daquela informação às autoridades competentes ou até ao público em geral é necessária em uma sociedade democrática.

Esse consenso internacional acerca da relevância e da urgência em se promover a proteção jurídica aos whistleblowers se refletiu no aumento da aprovação da legislação doméstica a respeito do assunto em diversos países, o que se deu ora por meio de leis dedicadas exclusivamente ao tema, ora por meio de disposições específicas em leis esparsas.

O levantamento mais abrangente sobre o panorama das normas nacionais de proteção aos reportantes foi divulgado em 2016 pela OCDE, a partir das informações prestadas por 32 países que responderam a uma pesquisa feita em 2014 a respeito da proteção a whistleblowers no setor público, complementado por dados obtidos pelo WGB nas avaliações feitas junto aos 41 países signatários da Convenção sobre Suborno Transnacional. Dos 32 países citados, 40,6\% possuem leis dedicadas, 43,8\% possuem leis dispersas e $15,6 \%$ não preveem nenhuma proteção legal a reportantes $\mathrm{OCDE}^{16}$.

Segundo a $\mathrm{OCDE}^{17}$, de 2010 a 2015 foram aprovadas mais leis exclusivas de proteção a whistleblowers (Eslováquia, Austrália, Bélgica, Hungria, Irlanda, Coréia do Sul e

16 OCDE.Commiting to effective whistleblower protection. Paris, 2016, p. 23. Disponível em: <dx.doi.org/10.1787/9789264252639-en>. Acesso em: 05 de janeiro de 2018.

17 OCDE.Commiting to effective whistleblower protection. Paris, 2016, p. 24. Disponível em: <dx.doi.org/10.1787/9789264252639-en>. Acesso em: 05 de janeiro de 2018. 
VARELLA, Marcelo D.; DEMATTÉ, Flávio R.. Limites e possibilidades de melhoria dos programas de whistleblowers para o combate à corrupção no brasil. Revista Eletrônica Direito e Política, Programa de Pós-Graduação Stricto Sensu em Ciência Jurídica da UNIVALI, Itajaí, v.15, n.2, 20 quadrimestre de 2020. Disponível em: www.univali.br/direitoepolitica - ISSN 1980-7791

Holanda) ${ }^{18}$ do que nos 25 anos anteriores (Canadá, Japão, Nova Zelândia, Reino Unido, Israel e EUA).

No que tange a medidas protetivas de reportantes no setor público, o relatório da OCDE apresenta as seguintes informações, tomando por base 27 países que responderam às questões:

(i) Em quase $100 \%$ dos países, infrações criminais, violações da lei e corrupção constituem atos ilícitos que ensejam proteção aos indivíduos que os denunciam $\mathrm{OCDE}^{19}$;

(ii) $85 \%$ dos países adotaram medidas para impedir reportantes de má fé, excluindo apenas Reino Unido, Portugal, Irlanda e Grécia OCDE ${ }^{20}$;

(iii) $59 \%$ dos países permitem que o whistleblowing seja feito de forma anônima $\mathrm{OCDE}^{21}$;

(iv) Apenas $30 \%$ dos países preveem incentivos para encorajar os whistleblowers: Austrália, Bélgica, Canadá, Coreia do Sul, Eslováquia, EUA, Israel e Japão $\mathrm{OCDE}^{22}$;

(v) $81 \%$ dos países contemplam punições àqueles que promovam retaliações aos whistleblowers, excluindo Chile, Estônia, Irlanda, Japão e México OCDE ${ }^{23}$.

\footnotetext{
18 Este número sobe para oito com a inclusão da Itália, que aprovou em novembro de 2017 uma lei específica que passou a prever um sistema de proteção a whistleblowers no ordenamento jurídico italiano. Se fosse considerar países que não são membros da OCDE e que promulgaram as suas leis de whistleblowing no referido período, o número seria ainda maior, a exemplo do Peru e da Malásia (2010), da Jamaica e da Índia (2011) e de Botsuana (2016).

19 OCDE. Commiting to effective whistleblower protection. Paris, 2016, p. 49. Disponível em: <dx.doi.org/10.1787/9789264252639-en>. Acesso em: 05 de janeiro de 2018.

20 OCDE. Commiting to effective whistleblower protection. Paris, 2016, p. 51. Disponível em: <dx.doi.org/10.1787/9789264252639-en>. Acesso em: 05 de janeiro de 2018.

${ }^{21}$ OCDE. Commiting to effective whistleblower protection. Paris, 2016, p. 64. Disponível em: <dx.doi.org/10.1787/9789264252639-en>. Acesso em: 05 de janeiro de 2018.

${ }^{22}$ OCDE. Commiting to effective whistleblower protection. Paris, 2016, p. 68. Disponível em: <dx.doi.org/10.1787/9789264252639-en>. Acesso em: 05 de janeiro de 2018.

${ }^{23}$ OCDE. Commiting to effective whistleblower protection. Paris, 2016, p. 83. Disponível em: <dx.doi.org/10.1787/9789264252639-en>. Acesso em: 05 de janeiro de 2018.
} 
VARELLA, Marcelo D.; DEMATTÉ, Flávio R.. Limites e possibilidades de melhoria dos programas de whistleblowers para o combate à corrupção no brasil. Revista Eletrônica Direito e Política, Programa de Pós-Graduação Stricto Sensu em Ciência Jurídica da UNIVALI, Itajaí, v.15, n.2, 20 quadrimestre de 2020. Disponível em: www.univali.br/direitoepolitica - ISSN 1980-7791

Já a respeito do whistleblowing no setor privado, o estudo da OCDE relata que:

(i) Dentro de um universo de 427 casos de suborno transnacional concluídos entre fevereiro de 1999 e junho de 2014, 17\% dos casos denunciados espontaneamente pelas empresas foram conhecidos por estas em razão de relatos de whistleblowers, terceira maior causa, ficando atrás apenas das constatações de auditoria interna (31\%) e dos procedimentos de due dilingence em fusões e aquisições (28\%) $\mathrm{OCDE}^{24}$;

(ii) Em um universo de 57 empresas de grande porte, 61\% responderam que possuem uma política escrita de proteção a reportantes $\operatorname{OCDE}^{25}$;

(iii) Em um universo de 58 empresas de grande porte, 53\% recebem os relatos de forma anônima e 38\% de maneira confidencial OCDE;

(iv) Os cinco tipos de ilícitos mais relatados pelos sistemas internos das empresas envolvem questões relacionadas a fraudes, saúde e segurança laboral, trabalho executado, privacidade e proteção de dados e suborno de funcionários públicos estrangeiros $\mathrm{OCDE}^{26}$;

(v) Mais da metade dos relatos feitos via sistemas internos das empresas são encaminhados e examinados pelo Chief Compliance Officer $\mathrm{OCDE}^{27}$.

Se, por um lado, o acolhimento do whistleblowing na legislação de diversos países tem se revelado um caminho sem volta, observa-se, por outro lado, uma tendência de profusão de leis que versam sobre a matéria no âmbito interno, inclusive com a coexistência de leis dedicadas e leis setoriais num mesmo país, como ocorre nos EUA.

A recomendação do relatório do $\mathrm{G}_{20} \mathrm{O}^{28}$ é que a adoção de leis dedicadas deveria ser priorizada, por oferecer mais clareza e certeza do que uma abordagem legislativa

\footnotetext{
${ }^{24}$ OCDE. Commiting to effective whistleblower protection. Paris, 2016, p. 117. Disponível em: <dx.doi.org/10.1787/9789264252639-en>. Acesso em: 05 de janeiro de 2018.

${ }^{25}$ OCDE. Commiting to effective whistleblower protection. Paris, 2016, p. 119. Disponível em: <dx.doi.org/10.1787/9789264252639-en>. Acesso em: 05 de janeiro de 2018.

${ }^{26}$ OCDE. Commiting to effective whistleblower protection. Paris, 2016, p. 122. Disponível em: <dx.doi.org/10.1787/9789264252639-en>. Acesso em: 05 de janeiro de 2018.

${ }^{27}$ OCDE. Commiting to effective whistleblower protection. Paris, 2016, p. 124. Disponível em: <dx.doi.org/10.1787/9789264252639-en>. Acesso em: 05 de janeiro de 2018.
} 
VARELLA, Marcelo D.; DEMATTÉ, Flávio R.. Limites e possibilidades de melhoria dos programas de whistleblowers para o combate à corrupção no brasil. Revista Eletrônica Direito e Política, Programa de Pós-Graduação Stricto Sensu em Ciência Jurídica da UNIVALI, Itajaí, v.15, n.2, 20 quadrimestre de 2020. Disponível em: www.univali.br/direitoepolitica - ISSN 1980-7791

fragmentada do tema. Segundo Ramirez ${ }^{29}$, a criação deliberada de várias leis torna o whistleblowing custoso e perigoso para o cidadão comum que deseja reportar, de sorte que uma legislação unificada e integrada de proteção aos reportantes ofereceria mais segurança a estes, auxiliaria de forma mais efetiva com os esforços em reprimir delitos e serviria melhor aos interesses da sociedade em assegurar o cumprimento da lei.

De todo modo, independentemente se pela via de uma lei dedicada ao tema ou por meio de disposições em legislação esparsa/setorial, o produto da atuação legislativa do Estado a respeito dos whistleblowers necessariamente precisará dispor sobre alguns aspectos essências que caracterizam esse instituto.

\section{ESTRUTURA NORMATIVA DE UM PROGRAMA DE ESTÍmULOS A REPORTANTES DE BOA-FÉ}

O papel da regulação de um programa de whistleblower pela via legal é conferir segurança jurídica às pessoas que desejam reportar atos ilícitos de que tenham conhecimento, o que exigirá que a lei ofereça uma estrutura normativa edificada em três pilares: (i) proteção do reportante; (ii) procedimento de divulgação (disclosure); e (iii) recompensas. Tais aspectos tangenciam, respectivamente, as dimensões pessoal, processual e retributiva dos programas.

A utilidade e a eficiência de um programa desta natureza estão diretamente associadas com a voluntariedade dos indivíduos em falar o que sabem, contudo estes não irão pessoalmente se expor sem que se sintam amparados por mecanismos legais que os protejam contra represálias ou sanções que eventualmente possam lhes ser impostas. Deste modo, a criação de uma rede de medidas protetivas em favor do reportante deve ser a preocupação primordial de uma legislação sobre o tema, pois

${ }^{28}$ G20. Study on whistleblower protection frameworks: compendium of best practices and guiding principles for legislation, 2012. P. 30. Disponível em: <www.oecd.org/g20/topics/anticorruption/48972967.pdf>. Acesso em: 06 de novembro de 2017.

29 RAMIREZ, Mary Kreiner. Blowing the whistle on whistleblower protection: a tale of reform versus power. University of Cincinnati Law Review, v. 76, n. 1, p. 183-233, 2007. Disponível em: <ssrn.com/abstract=1077881>. Acesso em: 06 de novembro de 2017. 
VARELLA, Marcelo D.; DEMATTÉ, Flávio R.. Limites e possibilidades de melhoria dos programas de whistleblowers para o combate à corrupção no brasil. Revista Eletrônica Direito e Política, Programa de Pós-Graduação Stricto Sensu em Ciência Jurídica da UNIVALI, Itajaí, v.15, n.2, 20 quadrimestre de 2020. Disponível em: www.univali.br/direitoepolitica - ISSN 1980-7791

será a avaliação deste aspecto a primeira a ser feita por indivíduos que se veem diante da escolha entre reportar ou não um ato ilícito de que tenham conhecimento.

Além da demissão, Banisar ${ }^{30}$ elenca outras formas mais sutis de retaliação: (i) retirar atribuições do empregado como forma de marginalizá-lo na organização; (ii) retirar credenciais dos servidores da segurança nacional, deixando-os, assim, efetivamente exonerados; (iii) rotular o empregado de forma depreciativa, fazendo com que fique sem condições de obter um emprego rentável; (iv) conduzir investigações retaliatórias para os fins de desviar a atenção do desperdício, da fraude ou do abuso que o whistleblower está buscando expor; (v) questionar a saúde mental do whistleblower, a sua competência profissional ou a sua honestidade; (vi) impor dificuldades ao whistleblower, atribuindo-Ihe tarefas de difícil ou impossível execução; (vii) transferir o empregado para outra localidade, deixando-o sem condições de realizar seu trabalho.

A possibilidade de imposição de eventuais represálias contra o reportante precisa ser completamente anulada por meio de uma proteção legislativa ampla e precisa, que confira a ele direitos claros que Ihe garantam a segurança necessária para reportar as informações a respeito de determinada ilicitude. Proposições legais deste teor reforçam a ideia de que o foco dos programas de whistleblowing é o conteúdo do que é reportado, e não a pessoa que reporta.

Além da repulsa a qualquer forma de retaliação, a Transparência Internacional ${ }^{31}$ indica alguns direitos decorrentes do princípio da proteção e que devem assegurados ao whistleblower pela via legal. O primeiro deles é a preservação da confidencialidade, a fim de garantir que a identidade do reportante só seja revelada com o seu consentimento. Também deve ser garantida a possibilidade de que a revelação das informações seja feita de forma anônima, lançando-se mão dos recursos tecnológicos necessários para impedir a identificação da origem da comunicação. Além disso, a

30 BANISAR, David. Whistleblowing: international standards and developments. Disponível em: <ssrn.com/abstract=1753180>. Acesso em: 20 de janeiro de 2018.

31 TRANSPARÊNCIA INTERNACIONAL. International principles for whistleblower legislation,2013.p.5. Disponível em: $<$ www.transparency.org/whatwedo/publication/international_principles_for_whistleblower_legislation>. Acesso em: 04 de novembro de 2017. 
VARELLA, Marcelo D.; DEMATTÉ, Flávio R.. Limites e possibilidades de melhoria dos programas de whistleblowers para o combate à corrupção no brasil. Revista Eletrônica Direito e Política, Programa de Pós-Graduação Stricto Sensu em Ciência Jurídica da UNIVALI, Itajaí, v.15, n.2, 20 quadrimestre de 2020. Disponível em: www.univali.br/direitoepolitica - ISSN 1980-7791

proteção do reportante deve prevalecer frente a sistemas de responsabilização administrativa, civil e criminal que possam estar relacionados com os atos ilícitos que está reportando, não podendo ele, por exemplo, ser acusado por difamação, violação de direitos autorais ou de dados. Mesmo compromissos de fidelidade à organização ou acordos de sigilo não afastam os direitos protetivos do reportante.

Isso não significa que uma pessoa esteja imune à sanções em caso de denúncias falsas contra seus empregadores, ou seja, quando não há boa-fé. Em um caso interessante, Deinisch vs. Alemanha, em 2011, a Corte Europeia de Direitos Humanos elencou de forma precisa os critérios para a eventual sanção a denunciantes. Tratavase de uma enfermeira que trabalhava em uma instituição estatal para idosos. A enfermeira alegava maus tratos aos idosos e omissões propositais em relatórios de gestão com o objetivo de evitar a efetividade da fiscalização feita pelos órgãos nacionais de controle de qualidade da prestação de serviços. Neste caso, haveria a prática de fraudes. As autoridades competentes da Alemanha consideravam que as denúncias não tinham fundamento e, sem uma investigação, encerraram o caso. A enfermeira acabou sendo demitida, sem aviso prévio, por violar a relação de confiança entre empregado e empregador. Mesmo após recorrer aos tribunais nacionais alemães, não houve reversão da demissão e da ausência de compensação.

$\mathrm{Na}$ análise da CEDH, confirmou-se que todo Estado deve ter um programa de proteção de reportantes, mesmo porque a proteção se enquadra como um direito fundamental no contexto da liberdade de expressão. A Corte também considerou que o cumprimento do dever de lealdade em relação ao empregador e a boa fé do reportante se concretizam com determinados passos antes de publicizar o ato: (a) a existência de canais alternativos para realização da denúncia; (b) a autenticidade das informações publicizadas; e (c) o reportante deve ter a intenção de enfrentar um ilícito. $^{32}$

Deve-se tentar primeiro reportar as denúncias aos órgãos internos, responsáveis por apurações, sobretudo quando há canais para esclarecimento de irregularidades. No caso específico, a reportante havia reportado irregularidades por três anos seguidos, sem qualquer investigação por parte dos seus empregadores. Caso o empregador

\footnotetext{
${ }^{32}$ A matriz de análise é repetida em diversos casos envolvendo julgamentos de reportantes pela CEDH, a exemplo dos casos citados.
} 
VARELLA, Marcelo D.; DEMATTÉ, Flávio R.. Limites e possibilidades de melhoria dos programas de whistleblowers para o combate à corrupção no brasil. Revista Eletrônica Direito e Política, Programa de Pós-Graduação Stricto Sensu em Ciência Jurídica da UNIVALI, Itajaí, v.15, n.2, 20 quadrimestre de 2020. Disponível em: www.univali.br/direitoepolitica - ISSN 1980-7791

tenha falhado na sua obrigação de investigar irregularidades, o empregado não mais está vinculado ao seu dever de lealdade em relação ao empregador e pode reportar os problemas a atores externos. Neste caso, os sistemas europeus prezam pela proteção dos dados internos da empresa, sobretudo aqueles que podem gerar concorrência desleal ou violação de direitos de propriedade intelectual. A divulgação ao público em geral ocorre apenas em última instância e de forma gradatativa Conseil d'Etat ${ }^{33}$.

Em outro contencioso, agora envolvendo a Moldávia, questionava-se a participação do próprio chefe do Ministério Público em atos de violência praticados por policiais. Relatórios internos denunciando os abusos foram enviados a imprensa e os responsáveis pela publicação foram punidos. Neste caso, considerou-se que, muito embora os trâmites internos não tenham sido seguidos, seria improvável que o próprio responsável pela investigação levasse a cabo um procedimento que culminaria com sua própria incriminação. ${ }^{34}$ Neste caso, não haveria canais alternativos para a realização da investigação, o que justificava o acesso direto à imprensa.

Assim, um pilar da estrutura normativa de programas de whistleblower reside na necessidade de que se defina como o indivíduo deve proceder para reportar um ato ilícito, ou seja, qual o procedimento de disclosure a ser seguido. A questão inicial que se impõe é estabelecer quem é a pessoa ou a instância competente para receber e examinar as informações a serem prestadas: compliance officer da organização, eventual unidade de auditoria externa, chefe imediato, alguma autoridade regulatória, determinados órgãos públicos, entidades externas (mídia, organizações profissionais) etc.

Juntamente com este ponto, mister que estejam claros quais os canais pelos quais o reportante pode encaminhar a sua comunicação e a forma como eles podem ser acessados. Os avanços tecnológicos na área de telecomunicações possibilitam a disponibilização de mecanismos de oferecimento de denúncias bem mais acessíveis e rápidos do que as clássicas hot lines telefônicas, devendo, contudo, estarem claros e

${ }^{33}$ CONSEIL d'ETAT. Le droit d'alerte: signaler, traiter protéger. Paris: La Documentation Française, 2016. p.57.

${ }^{34}$ CEDH. GUJA vs. Moldova. Decisão de 12 de fevereiro de 2008. 
VARELLA, Marcelo D.; DEMATTÉ, Flávio R.. Limites e possibilidades de melhoria dos programas de whistleblowers para o combate à corrupção no brasil. Revista Eletrônica Direito e Política, Programa de Pós-Graduação Stricto Sensu em Ciência Jurídica da UNIVALI, Itajaí, v.15, n.2, 20 quadrimestre de 2020. Disponível em: www.univali.br/direitoepolitica - ISSN 1980-7791

assegurados ao potencial whistleblower os níveis de sigilo e de confidencialidade que tais sistemas oferecem.

Dois aspectos importantes salientados pela $\mathrm{ONU}^{35}$ no que tange à dimensão processual dos programas é que se avalie (i) se a instância competente para receber as informações prestadas pelos whistleblowers será a mesma que ficará incumbida de analisar as queixas por eventuais represálias perpetradas contra o reportante, a fim de que se previna potenciais conflitos de interesse que podem surgir com a sobreposição de tais funções, e (ii) se os responsáveis por estas unidades terão um mandato.

Uma das principais contramedidas em caso de imposição de algum tipo de represália ao reportante é a atribuição do ônus da prova ao retaliador, cabendo a este demonstrar que as atitudes tomadas em relação ao reportante não possuem conexão com o fato deste ter relatado atos ilícitos. Assim, caberá ao acusado da retaliação comprovar, com evidências claras e convincentes, que a mesma medida teria sido imposta contra o reportante por motivos legais independentes do disclosure. De acordo com a ONU ${ }^{36}$, a inversão do ônus da prova nestes casos está prevista, por exemplo, nas leis anticorrupção e de whistleblowing da Croácia, França, Luxemburgo, Nova Zelândia, Noruega, Coréia do Sul, Eslovênia, Malásia, África do Sul, Reino Unido e EUA.

A Corte Europeia de Direitos Humanos reafirma, nos casos envolvendo whistleblowers, que a liberdade de expressão dos reportantes implica não só em direitos, mas também em obrigações. Há o dever de verificar cuidadosamente, de forma acurada e confiável, se há determinado ilícito relacionado àquilo que se está reportando, para

${ }^{35}$ ONU. Resource guide on good practices in the protection of reporting persons. Viena, 2015. p.71. Disponível em: $<$ www.unodc.org/documents/corruption/Publications/2015/15-

04741_Person_Guide_eBook.pdf>. Acesso em: 30 de novembro de 2017.

${ }^{36}$ ONU. Resource guide on good practices in the protection of reporting persons. Viena, $2015 . \quad$ p.64. Disponível em: $<$ www.unodc.org/documents/corruption/Publications/2015/15-

04741_Person_Guide_eBook.pdf>. Acesso em: 30 de novembro de 2017. 
VARELLA, Marcelo D.; DEMATTÉ, Flávio R.. Limites e possibilidades de melhoria dos programas de whistleblowers para o combate à corrupção no brasil. Revista Eletrônica Direito e Política, Programa de Pós-Graduação Stricto Sensu em Ciência Jurídica da UNIVALI, Itajaí, v.15, n.2, 20 quadrimestre de 2020. Disponível em: www.univali.br/direitoepolitica - ISSN 1980-7791

evitar a quebra do dever de lealdade e discrição em relação ao empregador. ${ }^{37}$ Os órgãos competentes pela avaliação das informações devem proceder de forma séria e investigar se houve ou não o ilícito. De qualquer modo, caso ocorram investigações ou o empregador consiga provar que não houve ilicitudes, nada impede que o reportante seja punido, com a demissão ou mesmo indenização.

Ainda que haja interesses monetários envolvidos com recompensas, o objetivo do reportante não pode ser apenas prejudicar o denunciado ou atacar de forma gratuita outra pessoa, mas corrigir um ilícito em curso.

Outro elemento estruturante de um programa de whistleblower a demandar uma regulação jurídica é o sistema de recompensas, sobretudo em casos de corrupção. Diferentemente das outras dimensões acima examinadas (pessoal e processual), a dimensão retributiva de tais programas ainda não está tão sedimentada nas legislações domésticas quanto aquelas, embora o $\mathrm{G}^{3} \mathrm{O}^{38}$ considere $\mathrm{o}$ ato de recompensar reportantes, inclusive com prêmios financeiros, como uma boa prática a ser observada pelos países.

Rocha $^{39}$ aponta que as premiações a whistleblowers podem ser justificadas de quatro formas: (i) servem como fomento para romper com a cultura do silêncio; (ii) consistem em meras retribuições pelo esforço dispendido pelo reportante; (iii) funcionam como compensação diante de eventuais falhas dos mecanismos protetivos; e (iv) valorizam o ato de relatar como uma contribuição em favor do interesse público.

\footnotetext{
37 Ver as seguintes decisões da CEDH: (i) Handyside vs. Reino Unido, de 07 de dezembro de 1976, § 49, Series A no. 24 e (ii) Haseldine vs. Reino Unido, no. 18957/91, decisão da Comissão de 13 de maio de 1992.

38 G20. Study on whistleblower protection frameworks: compendium of best practices and guiding principles for legislation, 2012. p.32. Disponível em: <www.oecd.org/g20/topics/anticorruption/48972967.pdf>. Acesso em: 06 de novembro de 2017.

39 ROCHA, Márcio Antônio. Subsídios ao debate para a implantação dos programas de whistleblower no Brasil. Revista de Doutrina da 4a Região, Porto Alegre, n. 75, dez. 2016. p.30. Disponível em: $<$ www.revistadoutrina.trf4.jus.br/artigos/edicao075/Marcio_Rocha.html>. Acesso em: 07 de novembro de 2017.
} 
VARELLA, Marcelo D.; DEMATTÉ, Flávio R.. Limites e possibilidades de melhoria dos programas de whistleblowers para o combate à corrupção no brasil. Revista Eletrônica Direito e Política, Programa de Pós-Graduação Stricto Sensu em Ciência Jurídica da UNIVALI, Itajaí, v.15, n.2, 20 quadrimestre de 2020. Disponível em: www.univali.br/direitoepolitica - ISSN 1980-7791

Os resultados econômicos positivos gerados pelos sistemas de recompensas a whistleblowers utilizados nos EUA pela Securities and Exchange Commission (SEC) ${ }^{40} \mathrm{e}$ pela Internal Revenue Service (IRS) ${ }^{41}$ - respectivamente, a Comissão de Valores Mobiliários e Receita Federal norte-americanas - têm contribuído para uma maior aceitação de mecanismos desta natureza no cenário internacional, mitigando, assim, os argumentos de natureza moral e ética que comumente são levantados contra eles, sendo o mais comum o de que não se deve recompensar quem fez o que tinha obrigação de fazer.

As escolhas legislativas acerca de um sistema de recompensas a whistleblowers devem examinar não apenas se é apropriada a criação de tal mecanismo para determinada área (por exemplo, anticorrupção, fiscal, antitruste etc.), mas também que tipos de atos ilícitos a serem reportados serão passíveis de gerar premiações e quais as formas de retribuição previstas.

Por fim, é importante ressaltar que a opção do legislador por introduzir em determinado ordenamento jurídico um sistema de recompensas a reportantes precisará estar em harmonia com a conjuntura social, econômica e cultural daquele país, sob pena de desestimular os cidadãos a se tornarem potenciais whistleblowers. Em pesquisa desenvolvida acerca da efetividade de recompensas e deveres

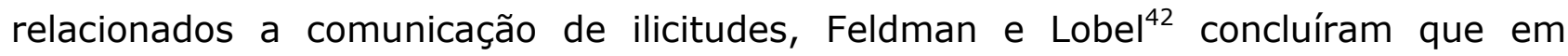
sociedades onde o respeito à lei é capaz de despertar uma forte motivação ética interna, o oferecimento de prêmios monetários pode ser contraproducentes, por

\footnotetext{
${ }^{40}$ Segundo o Dodd-Frank Act, aplicável ao setor de valores mobiliários, whistleblowers que contribuam com informações que resultem em sanções superiores a US\$1 milhão serão recompensados pela SEC com um valor que variará entre $10 \%$ e $30 \%$ do total de sanções pecuniárias arrecadadas. Segundo o relatório anual apresentado pela SEC ao Congresso norte-americano, foram pagos quase US\$ 142 milhões a whistleblowers no ano fiscal de 2019, o que, fazendo uma conta reversa, implicou em uma arrecadação de, no mínimo, de US\$ 473 milhões (SEC, 2019, p. 28).

41 Segundo o Internal Revenue Code, whistleblowers que contribuam com informações a respeito de sonegação fiscal superior a US\$2 milhões, em caso de empresas, ou que envolva pessoas físicas com renda anual superior a US\$200 mil serão recompensados pela IRS com um valor que variará entre $15 \%$ e $30 \%$ do total que venha a ser arrecadado a partir e em razão do disclosure. Segundo o relatório anual apresentado pela IRS ao Congresso norte-americano, foram pagos cerca de US\$120,3 milhões a whistleblowers no ano fiscal de 2019, ao passo que no mesmo período foram arrecadados US\$ 616,8 milhões (IRS, 2019, p. 8).

42 FELDMAN, Yuval; LOBEL, Orly. The Incentives Matrix: the comparative effectiveness of rewards, liabilities, duties and protections for reporting illegality. Texas Law Review, v. 87, 2010. p.4. Disponível em: <ssrn.com/abstract=1415663>. Acesso em: 18 de dezembro de 2017.
} 
VARELLA, Marcelo D.; DEMATTÉ, Flávio R.. Limites e possibilidades de melhoria dos programas de whistleblowers para o combate à corrupção no brasil. Revista Eletrônica Direito e Política, Programa de Pós-Graduação Stricto Sensu em Ciência Jurídica da UNIVALI, Itajaí, v.15, n.2, 20 quadrimestre de 2020. Disponível em: www.univali.br/direitoepolitica - ISSN 1980-7791

aparentarem moralmente ofensivos; nestes casos, os autores entendem que a simples criação de dever de reportar já seria suficiente.

Bugarin e Bugarin ${ }^{43}$ possuem entendimento semelhante e argumentam que a premiação daqueles que contribuem para o controle da corrupção, incluindo aí os whistleblowers, produzirá efeitos antagônicos de acordo com o nível de desigualdade de renda existente em determinada sociedade. Em sociedades heterogêneas, marcadas por alta desigualdade social, como os EUA, prevalece entre os cidadãos sobretudo os das classes mais baixas - um sentimento de distanciamento e de não pertencimento àquele corpo social; nesse contexto, os cidadãos tenderão a valorizar algum retorno pecuniário que lhes seja oferecido pela colaboração que prestarem e não se sentirão moralmente constrangidos por isso, o que incentivaria o controle social. Por outro lado, em sociedades homogêneas, onde a desigualdade de renda seja baixa, como a Suíça, os cidadãos se veem como membros importantes daqueles grupos sociais; em um ambiente como este, pode soar ofensivo para as pessoas o oferecimento de valores pecuniários em retribuição ao controle por elas exercido sobre a coisa pública, o que pode desestimular o envolvimento social nessa seara.

Após a análise das três dimensões que compõem a estrutura normativa dos programas de whistleblowers, verifica-se que recai sobre o legislador a responsabilidade de regular, via direito positivo, os diversos aspectos relacionados à proteção do reportante, ao procedimento de reportar e às recompensas cabíveis. Sem leis claras e precisas a respeito destes pontos, não haverá a segurança jurídica necessária para criar um ambiente normativo propício ao disclosure de atos ilícitos como a corrupção. Referindo-se ao whistleblowing no setor público, o relatório do $\mathrm{G} 20^{44}$ (2012, p. 15) estampa recomendação de igual teor:

39. Como resultado, o encorajamento de relatos deve estar associado a uma correspondente proteção para o whistleblower.

\footnotetext{
43 BUGARIN, Maurício Soares; BUGARIN, Tomás Tenshin Sataka. Ética \& Incentivos: devemos recompensar quem denuncia corrupção? Revista Direito GV, São Paulo, v. 13, n. 2, p. 402, mai-ago 2017.

44 G20. Study on whistleblower protection frameworks: compendium of best practices and guiding principles for legislation, 2012. p.15. Disponível em: <www.oecd.org/g20/topics/anticorruption/48972967.pdf>. Acesso em: 06 de novembro de 2017.
} 
VARELLA, Marcelo D.; DEMATTÉ, Flávio R.. Limites e possibilidades de melhoria dos programas de whistleblowers para o combate à corrupção no brasil. Revista Eletrônica Direito e Política, Programa de Pós-Graduação Stricto Sensu em Ciência Jurídica da UNIVALI, Itajaí, v.15, n.2, 20 quadrimestre de 2020. Disponível em: www.univali.br/direitoepolitica - ISSN 1980-7791

No setor público, os servidores públicos precisam saber quais são os seus direitos e as suas obrigações em termos de expor suspeitas de irregularidades dentro do serviço público. Esses devem incluir regras e procedimentos claros para serem seguidos por oficiais em uma cadeia formal de responsabilidades. Os servidores públicos também devem saber qual a proteção que será disponibilizada a eles em caso de exporem irregularidades.

40. Traduzir a proteção do whistleblower em legislação legitima e estrutura um mecanismo pelo qual os oficiais públicos podem revelar irregularidades no setor público, protege os servidores públicos contra represálias e, ao mesmo tempo, os encoraja a cumprirem seus deveres de atuar eficientemente, com transparência e com alta qualidade de serviços públicos.

Mas a segurança que decorre das normas jurídicas não é o único fator que influencia a decisão de se tornar um whistleblower. Há também fatores de ordem comportamental que poderão conduzir um potencial reportante a optar por não falar, por mais racional que seja a opção de escolher reportar.

\section{O USO DE ESTÍMULOS COMPORTAMENTAIS COMO FORMA DE AMPLIAÇÃO DA EFETIVIDADE DOS PROGRAMAS}

Se é na lei que um indivíduo precisa encontrar segurança jurídica para "soprar o apito", será explorando insights comportamentais que o setor privado e o Estado estimularão um potencial reportante a decidir por sair da inércia e reportar atos ilícitos de que tenha conhecimento. Ou seja, é a integração entre estrutura normativa e arquitetura de escolhas que tornará efetivo um programa de whistleblower. É nesta seara que ganham relevância os aportes da economia comportamental.

Marcada por um diálogo com a psicologia, a economia comportamental se dedica ao estudo da influência do comportamento das pessoas nas suas decisões de natureza econômica, as quais tendem a ser tomadas por meio de atalhos mentais (heurísticas), que podem distorcer a racionalidade do processo decisório (vieses).

É possível traçar um resumido histórico da evolução da economia comportamental a partir de três marcos acadêmicos. Ela tem a sua origem em meados da década de 1950 com os estudos desenvolvidos por Herbert Simon, que buscou revisar o tradicional conceito de homo economicus, um dos pilares da economia neoclássica, e 
VARELLA, Marcelo D.; DEMATTÉ, Flávio R.. Limites e possibilidades de melhoria dos programas de whistleblowers para o combate à corrupção no brasil. Revista Eletrônica Direito e Política, Programa de Pós-Graduação Stricto Sensu em Ciência Jurídica da UNIVALI, Itajaí, v.15, n.2, 20 quadrimestre de 2020. Disponível em: www.univali.br/direitoepolitica - ISSN 1980-7791

questionar os pressupostos de racionalidade ilimitada e de ordem de preferências completa, imanentes a este conceito. De acordo com Simon ${ }^{45}$, o homem real não busca o caminho da otimização máxima em suas escolhas, contendo-se com o caminho da satisfação das suas necessidades.

O segundo salto evolutivo da economia comportamental se dá vinte anos depois com os trabalhos de Daniel Kahneman e Amos Tversky ${ }^{46}$ a respeito da tendência das pessoas tomarem suas decisões por meio de heurísticas ${ }^{47}$ e de como esse processo de simplificação cognitiva é afetado por três vieses comportamentais: representatividade, que consiste na probabilidade de alguém classificar/associar algo como pertencente a determinada classe ou grupo; (ii) disponibilidade, que diz respeito à avaliação da frequência ou da plausibilidade da ocorrência de algo a partir da facilidade com que isso vem à mente da pessoa; e (iii) ancoragem, que se relaciona à tendência de alguém não realizar grandes ajustes na avaliação inicial que faz acerca de determinado objeto ou situação.

As ideias sobre estímulos comportamentais se tornam mais famosas com a atribuição de dois prêmios Nobel de economia, primeiro ao psicólogo Daniel Hahneman, em 2002, e, depois, em 2017, ao economista Richard Thaler. Thaler, em uma obra clássica com Cass Sunstein ${ }^{48}$, parte da ideia de arquitetura de escolhas - isto é, a organização do contexto no qual as pessoas tomam suas decisões - para apresentar o conceito de nudge ou, em português, "cutucada", que consiste em "em qualquer aspecto da arquitetura de escolhas que altera o comportamento das pessoas de maneira previsível sem proibir nenhuma opção nem mudar significativamente seus incentivos econômicos". Segundo os autores, sua teoria seria libertária, por insistir na

${ }^{45}$ SIMON, Herbert. Rational choice and the structure of the environment. Psychological Review, n. 63, p. 136, $1956 . \quad$ Disponível em: <http://digitalcollections.library.cmu.edu/awweb/awarchive?type=file\&item=33544>. Acesso em: 10 de novembro de 2017.

46 KAHNEMAN, Daniel; TWERSKY, Amos. Judgment under uncertainty: heuristics and biases. Science, New Series, v. 185, n. 4157, p. 1124, 1974. Disponível em: <psiexp.ss.uci.edu/research/teaching/Tversky_Kahneman_1974.pdf >. Acesso em: 10 de novembro de 2017.

47 O conceito de heurística é oriundo da psicologia - Kahnemam e Tversky são psicológos, e não economistas - e que corresponde a atalhos mentais empregados pelas pessoas para simplificar e acelerar o processo cognitivo de tomada de decisões.

${ }^{48}$ A edição em português do livro foi publicada no Brasil em 2009 com o título "Nudge: o empurrão para a escolha certa". Será esta a versão utilizada nas citações feitas neste artigo. 
VARELLA, Marcelo D.; DEMATTÉ, Flávio R.. Limites e possibilidades de melhoria dos programas de whistleblowers para o combate à corrupção no brasil. Revista Eletrônica Direito e Política, Programa de Pós-Graduação Stricto Sensu em Ciência Jurídica da UNIVALI, Itajaí, v.15, n.2, 20 quadrimestre de 2020. Disponível em: www.univali.br/direitoepolitica - ISSN 1980-7791

liberdade das pessoas de fazerem o que quiserem e, ao mesmo tempo, paternalista, por entender que seria legítima a influência exercida por arquitetos de escolhas para tentar influenciar o comportamento das pessoas em direção a situações que possam melhorar as suas vidas.

A $\mathrm{OCDE}^{49}$ aponta que a área de integridade nos setores públicos e privados é um campo muito propenso a transformações significativas através da abordagem comportamental, sobretudo com o fim de transformar a integridade em algo ligado ao sentimento de confiança e de honestidade nas organizações públicas e privadas, ao invés de ser apenas o resultado dos controles exercidos.

É nesse contexto que as reflexões oriundas das pesquisas comportamentais podem contribuir para estimular as pessoas a tomarem a posição de whistleblower, na medida em que um comportamento proativo por parte dos indivíduos em falar sobre atos ilícitos de que tem conhecimento é um elemento central em qualquer política anticorrupção desenvolvida pelo Estado ou pelas organizações privadas.

O desafio que se apresenta para os arquitetos de escolhas nestes casos é como lidar com o dilema enfrentado pelo indivíduo que detém informações acerca de determinada ilicitude: reportar o que sabe ou fechar os olhos para evitar problemas. Confiar apenas na disposição comportamental e na régua moral das pessoas quanto à escolha, por estas, de reportar ou não é um risco muito elevado para uma organização que deseja prevenir e coibir a prática de atos ilícitos que possam gerar repercussões para ela.

A partir da segurança jurídica proporcionada pelas leis que regulam os programas de whistleblowers, caberá às organizações públicas e privadas desenvolverem mecanismos que estimulem comportamentalmente os indivíduos a reportar, a fim de que se estabeleça uma cultura de whistleblowing.

Um primeiro ponto a ser desenvolvido pelas organizações junto aos indivíduos é a clareza quanto à abrangência e o funcionamento do programa. As pessoas precisam

49 OCDE. Behavioural Insights and Public Policy: lessons from around the world. Paris, 2017. p.50.Disponível em: <dx.doi.org/10.1787/9789264270480-en>. Acesso em: 02 de agosto de 2017. 
VARELLA, Marcelo D.; DEMATTÉ, Flávio R.. Limites e possibilidades de melhoria dos programas de whistleblowers para o combate à corrupção no brasil. Revista Eletrônica Direito e Política, Programa de Pós-Graduação Stricto Sensu em Ciência Jurídica da UNIVALI, Itajaí, v.15, n.2, 20 quadrimestre de 2020. Disponível em: www.univali.br/direitoepolitica - ISSN 1980-7791

saber quais são os tipos de condutas indevidas que devem ser relatadas, como está procedimentalmente desenhado o caminho a ser percorrido pelo indivíduo que opte por reportar e quem será o responsável por analisar as informações que vier a prestar. Objetivando o rompimento da inércia e da procrastinação por parte dos indivíduos, todos estes aspectos devem ser estruturados e apresentados de maneira simples, de fácil compreensão e de rápido acesso.

Dentre as medidas que o $B I T$ propõe a respeito de como uma abordagem comportamental pode impactar positivamente as políticas anticorrupção, a utilização de plataformas digitais acessíveis e desenvolvidas de forma amigável tem o potencial de servir como um instrumento importante para estimular um whistleblowing em tempo real $\mathrm{BIT}^{50}$.

Outro instrumento que contribui para um comportamento proativo de reportar é a implantação, pela organização, de mecanismos que demonstrem que a confidencialidade das comunicações e a identidade do whistleblower estão asseguradas. A contratação de uma entidade externa responsável pelo whistleblowing e o emprego de tecnologias de segurança de dados nos canais disponíveis para reportar são exemplos de medidas que, se implantadas, têm a capacidade de transmitir aos potenciais whistleblowers a mensagem de que o ato de reportar é seguro e de baixo risco, o que pode contribuir para minimizar o sentimento de aversão a perdas.

A existência de um sistema de retribuição aos reportantes pode servir como estímulo para a prática de reportar. Em que pese a necessidade de previsão legal para que o setor público recompense financeiramente os reportantes, as organizações privadas possuem ampla margem de liberdade nesse ponto, o que não as isentará de fazer uma meticulosa avaliação acerca do impacto que um mecanismo desta natureza teria sobre o ambiente organizacional da entidade.

Por outro lado, premiações de natureza não financeira passam ao largo das questões legais e éticas que costumam ser levantadas contra os prêmios monetários. Se o ato

50 BIT. Corruption: can a behavioural approach shift the dial?, 2016. Disponível em: <www.behaviouralinsights.co.uk/international/corruption-can-a-behavioural-approach-shift-the-dial/>. Acesso em 06 de novembro de 2017. 
VARELLA, Marcelo D.; DEMATTÉ, Flávio R.. Limites e possibilidades de melhoria dos programas de whistleblowers para o combate à corrupção no brasil. Revista Eletrônica Direito e Política, Programa de Pós-Graduação Stricto Sensu em Ciência Jurídica da UNIVALI, Itajaí, v.15, n.2, 20 quadrimestre de 2020. Disponível em: www.univali.br/direitoepolitica - ISSN 1980-7791

de reportar um ato ilícito está associado à preservação da integridade da organização, é natural que o whistleblower almeje que a sua atitude seja reconhecida pelos outros como um modelo de dedicação e compromisso com os valores organizacionais coletivamente compartilhados.

Nesse sentido, uma política de agradecimento pelo whistleblowing, que reconheça a importância do ato praticado pelo indivíduo em prol da integridade da organização, seria uma forma de retribuição não financeira aos reportantes, ao mesmo tempo em que a divulgação de um caso bem-sucedido de whistleblowing pode contribuir para que outros sigam o mesmo exemplo, promovendo, assim, um efeito "manada" positivo. Rangone ${ }^{51}$ aponta ainda como exemplos de soluções capazes de influenciar o comportamento das pessoas em direção ao ato de reportar o envio de um feedback ao reportante relatando as medidas que foram adotadas a partir do whistleblowing e o treinamento contínuo do corpo funcional.

Do que foi examinado até aqui, pode-se concluir que a efetividade de um programa de whistleblower depende de uma simbiose entre a estrutura normativa decorrente da lei e a arquitetura de escolhas desenvolvida pela organização, seja ela pública ou privada. Ao passo que, por exemplo, aspectos relacionados à proteção do reportante dependerão precipuamente dos contornos legais estabelecidos pelo Estado, como a não persecução civil ou criminal do whistleblower por questões relacionadas ao que reportou, assuntos relacionados ao processo e ao procedimento para exercício do whistleblowing serão solucionados essencialmente por meio das políticas de governança e integridade adotadas pelas organizações. A lei depende da arquitetura de escolhas para ser implementada e executada na prática e a arquitetura de escolhas depende da lei para gerar segurança jurídica às pessoas.

\section{A PROTEÇÃo AOS REPORTANTES DE BOA-FÉ NO BRASIL}

Com grande atraso em relação a outros países, só recentemente o debate sobre os whistleblower entrou na agenda anticorrupção brasileira, o que se observa com a tramitação de alguns projetos de lei no Congresso Nacional e com a inclusão de uma

${ }^{51}$ RANGONE, Nicoletta. A behavioural approach to administrative corruption prevention. 2016. Disponível em: <ssrn.com/abstract=2881878>. Acesso em: 04 de novembro de 2017. 
VARELLA, Marcelo D.; DEMATTÉ, Flávio R.. Limites e possibilidades de melhoria dos programas de whistleblowers para o combate à corrupção no brasil. Revista Eletrônica Direito e Política, Programa de Pós-Graduação Stricto Sensu em Ciência Jurídica da UNIVALI, Itajaí, v.15, n.2, 20 quadrimestre de 2020. Disponível em: www.univali.br/direitoepolitica - ISSN 1980-7791

ação específica na Estratégia Nacional de Combate à Corrupção e à Lavagem de Dinheiro ENCCLA ${ }^{52}$. Contudo, verifica-se em tais medidas algumas deficiências que dificultam a harmonização do binômio "estrutura normativa x arquitetura de escolha" necessário a um programa de whistleblower.

Em termos de norma positivada, os whistleblowers são mencionados de forma superficial e indireta apenas na parte final do inciso $X$ do art. 42 do Decreto no 5.480 , de 2015, que regulamentou a Lei no 12.846, de 2013, a chamada "Lei Anticorrupção". O referido dispositivo prevê que dentre os parâmetros a serem utilizados para avaliação dos programas de integridade de pessoas jurídicas está a existência e a aplicação de "canais de denúncia de irregularidades, abertos e amplamente divulgados a funcionários e terceiros, e de mecanismos destinados à proteção de reportantes de boa-fé".

Em janeiro de 2018 foi publicada a Lei no 13.608, que passou a autorizar a União, os Estados, o Distrito Federal e os Municípios a estabelecer formas de recompensa, inclusive com valores em espécie, pelo oferecimento de informações que sejam úteis para a prevenção, a repressão ou a apuração de crimes ou ilícitos administrativos ${ }^{53}$. Em que pese se refira brevemente acerca de um sistema de recompensas, tal lei não pode ser compreendida como uma genuína legislação whistleblower por não trazer, também, nenhuma regra que disponha sobre proteção a reportantes ou o processo de whistleblowing. Mesmo o tema da premiação foi abordado de forma meramente tangencial, transferindo-se para os entes da Federação a regulamentação da matéria.

Um importante passo em direção a uma matriz normativa de proteção a whistleblower foi dado pelo Poder Executivo Federal com a edição do Decreto no 10.153, de 03/12/2019, que dispõe sobre as salvaguardas de proteção à identidade dos denunciantes de ilícitos e de irregularidades praticados contra a administração pública federal direta e indireta.

\footnotetext{
52 Vale registrar que embora o tema tenha sido objeto da Ação 4 da ENCCLA 2016, debatida durante o ano de 2015, ele não retornou nas ações debatidas nos anos seguintes. Um relatório foi produzido acerca do tema (ENCLLA, 2016).

53 "Art. 4ํㅜ A União, os Estados, o Distrito Federal e os Municípios, no âmbito de suas competências, poderão estabelecer formas de recompensa pelo oferecimento de informações que sejam úteis para a prevenção, a repressão ou a apuração de crimes ou ilícitos administrativos.

Parágrafo único. Entre as recompensas a serem estabelecidas, poderá ser instituído o pagamento de valores em espécie."
} 
VARELLA, Marcelo D.; DEMATTÉ, Flávio R.. Limites e possibilidades de melhoria dos programas de whistleblowers para o combate à corrupção no brasil. Revista Eletrônica Direito e Política, Programa de Pós-Graduação Stricto Sensu em Ciência Jurídica da UNIVALI, Itajaí, v.15, n.2, 20 quadrimestre de 2020. Disponível em: www.univali.br/direitoepolitica - ISSN 1980-7791

Embora a fundamentação legal do referido decreto não seja a mencionada Lei no 13.608, de 2018, e sim a Lei no 13.460, de 26/06/2017, que trata da participação, proteção e defesa dos direitos do usuário dos serviços públicos da administração pública, estabeleceu-se ali balizas que podem favorecer uma atitude comportamentalmente orientada por parte de reportantes, tais como: (i) a definição das instâncias que receberão as denúncias, no caso as unidades de ouvidoria; (ii) a imposição de um dever de preservação dos elementos de identificação do denunciante, por meio do sigilo do nome, do endereço e de quaisquer outros elementos que possam identificá-lo; e (iii) a previsão de que o encaminhamento da denúncia com os elementos de identificação do denunciante se dê mediante a pseudonimização destes elementos ${ }^{54}$.

Ainda em dezembro de 2019, três novos artigos foram incluídos na Lei no 13.608, de 2018, no bojo das reformas legislativas encampadas pela Lei no 13.964, de 26/12/2019, a qual é fruto das discussões envolvendo o chamado "Pacote Anticrime" ${ }^{\prime 55}$. Além de incorporar em uma lei em sentido estrito diversos aspectos que haviam sido recentemente regulamentados pelo Decreto no 10.153, de 2019, um grande avanço normativo foi alcançado com o novo art. 40-C, que dispõe sobre a proteção do informante contra ações ou omissões praticadas em retaliação ao exercício do direito de relatar, a exemplo da demissão arbitrária, da alteração injustificada de funções ou atribuições, de prejuízos remuneratórios ou materiais de qualquer espécie e da negativa de fornecimento de referências profissionais positivas.

Indo além, as novas disposições legais também asseguram ao informante o ressarcimento em dobro por eventuais danos materiais causados por ações ou omissões praticadas em retaliação ao exercício do direito de relatar, sem prejuízo de danos morais, bem como possibilita que seja fixada recompensa em favor do informante em até $5 \%$ do valor recuperado, caso as informações por ele

\footnotetext{
${ }^{54}$ Segundo o inciso II do art. $3^{\circ}$ do Decreto no 10.153, de 2019, a pseudonimização consiste no tratamento por meio do qual um dado perde a possibilidade de associação, direta ou indireta, a um indivíduo, senão pelo uso de informação adicional mantida separadamente pelo controlador em ambiente controlado e seguro.

55 O conteúdo da Lei no 13.964, de 2019, é formado, em grande parte, pelos textos do Projeto de Lei no 882/2019, idealizado pelo ex-Ministro da Justiça Sérgio Moro, e do Projeto de Lei no 10.372/2018, preparado por uma comissão de juristas presidida pelo Ministro do STF Alexandre de Moraes.
} 
VARELLA, Marcelo D.; DEMATTÉ, Flávio R.. Limites e possibilidades de melhoria dos programas de whistleblowers para o combate à corrupção no brasil. Revista Eletrônica Direito e Política, Programa de Pós-Graduação Stricto Sensu em Ciência Jurídica da UNIVALI, Itajaí, v.15, n.2, 20 quadrimestre de 2020. Disponível em: www.univali.br/direitoepolitica - ISSN 1980-7791

disponibilizadas resultem em recuperação de produto de crime contra a administração pública.

Não obstante o progresso do quadro normativo sobre a matéria, verifica-se que o legislador ordinário transferiu para o âmbito da regulamentação infralegal a tarefa de melhor elucidar e detalhar o modo como essas garantias e direitos do reportante serão implementadas, o que é fundamental para o desenvolvimento de uma arquitetura de escolhas que estimule uma cultura comportamental de relatar a ocorrência de irregularidades.

\section{PROPOSTAS DE MELHORIA}

De certa forma, esse artigo viabiliza avançar significativamente na regulamentação dos benefícios aos reportantes, tal como na estruturação proposta pela ENCCLA ${ }^{56}$. Ainda que seja necessário um ato para cada ente da federação envolvido, o Poder Executivo Federal poderia tomar a frente do processo e elaborar uma "normamodelo", a qual poderia facilmente ser multiplicada pelos Estados. Em que pese a recente edição do Decreto no 10.153, de 2019, seria recomendável uma regulamentação federal que avançasse ainda mais, seguindo as linhas indicadas no relatório da ENCCLA e, em especial, fundado nos artigos $4^{\circ}$ a $4^{\circ}-\mathrm{C}$ da Lei 13.608 , de 2018, poderia conter:

a) Vinculação de todos os órgãos, autarquias e entidades federais;

b) Criação de comissões para recebimento e apuração de relatos, com tratamento sigiloso das informações recebidas e proteção aos reportantes, com competências de investigação e avaliação dos ilícitos noticiados;

c) Proteção tanto de assalariados, como de prestadores de serviço, estagiários ou mesmo empresas terceirizadas ou parceiras (Conselho de Estado, 2016, p. 59);

56 ENCCLA. Subsídios para implantação de programas de whistleblower no Brasil, 2016. Disponível em: <http://enccla.camara.leg.br/biblioteca/artigos/whistleblower-1/subsidios-para-implantacao-deprogramas-de-whistleblower-no-brasil/at_download/file>. Acesso em: 23 de fevereiro de 2018. 
VARELLA, Marcelo D.; DEMATTÉ, Flávio R.. Limites e possibilidades de melhoria dos programas de whistleblowers para o combate à corrupção no brasil. Revista Eletrônica Direito e Política, Programa de Pós-Graduação Stricto Sensu em Ciência Jurídica da UNIVALI, Itajaí, v.15, n.2, 20 quadrimestre de 2020. Disponível em: www.univali.br/direitoepolitica - ISSN 1980-7791

d) Criação de procedimentos amplamente acessíveis, com base em uma conciliação clara entre o direito de alerta e as disposições existentes para a proteção de segredos do comércio;

e) Proteção do reportante, ao menos que não haja boa-fé ou sejam falsas as informações, com a preservação da sua identidade, não demissão ou outras formas de punição, apoio psicológico, autorização temporária para trabalho domiciliar ou afastamento, entre outros;

f) Fixação de medidas de incentivo, como pagamentos em espécie, proporcionais aos fatos relatados, nos moldes do praticado nos Estados Unidos e na Europa.

Além destes problemas, nota-se falhas na dimensão processual dos programas de whistleblowers. A não previsão da inversão do ônus da prova e as diversas exigências formais para a revelação de informação ${ }^{57}$ são omissões graves que não colocam 0 projeto de lei em harmonia com as boas práticas recomendadas pelo G20 e pela Transparência Internacional e com as legislações estrangeiras mais modernas.

De todas as propostas da ENCCLA, a única relevante que não poderia ser implementada por decreto é a previsão de sanções para aqueles que praticarem atos contra a lei, mas isso não impede que outros tipos penais mais genéricos ou sanções típicas de direito administrativo já previstas no ordenamento jurídico incidam nestes casos. Trata-se de boa oportunidade de regulamentação por meio de ato infralegal.

\section{CONSIDERAÇÕES FINAIS}

Embora os programas de whistleblower tenham se consolidado em outros países como instrumentos essenciais para a identificação de atos ilícitos, sobretudo daqueles de difícil apuração, como a corrupção, o Brasil ainda não conta com um aparato normativo estruturado que regule o whistleblowing, em que pese as repetidas obrigações assumidas quanto ao tema em tratados anticorrupção.

\footnotetext{
57 Art. $4^{\circ}$ A revelação de informação de interesse público poderá ser realizada por escrito ou oralmente, devendo ser reduzida a termo e assinada, e conterá: I - a qualificação do autor da revelação; II - a intenção, propósito, motivo ou razões para a revelação da informação; III - a descrição das ações ou omissões objeto da revelação e a indicação de provável autoria; IV - informações detalhadas sobre os fatos revelados; $\mathrm{V}$ - a indicação das provas de que tenha conhecimento.
} 
VARELLA, Marcelo D.; DEMATTÉ, Flávio R.. Limites e possibilidades de melhoria dos programas de whistleblowers para o combate à corrupção no brasil. Revista Eletrônica Direito e Política, Programa de Pós-Graduação Stricto Sensu em Ciência Jurídica da UNIVALI, Itajaí, v.15, n.2, 20 quadrimestre de 2020. Disponível em: www.univali.br/direitoepolitica - ISSN 1980-7791

Ao examinar a experiência legislativa estrangeira e os estudos elaborados em fóruns internacionais, o presente trabalho apontou que a regulação de um programa de whistleblower pela via legal deve perpassar por propostas que ofereçam uma estrutura normativa edificada em três pilares: (i) proteção do reportante - dimensão pessoal; (ii) procedimento de divulgação (disclosure) - dimensão processual; e (iii) recompensas - dimensão retributiva. Tem a lei, assim, o papel de conferir segurança jurídica para a prática do whistleblowing.

Por outro lado, restou assentado que a exploração de insights comportamentais pelo setor privado e pelo Estado é essencial para estimular potenciais reportantes a decidir por sair da inércia e relatar atos ilícitos de que tenham conhecimento. Ou seja, a integração entre estrutura normativa e arquitetura de escolhas é onde se encontra a raiz da efetividade de um programa de whistleblower.

Foi visto ainda, que os projetos de leis em curso no Congresso Nacional não se apresentam como propostas que ofereçam segurança jurídica para a sedimentação do whistleblowing no Brasil. Em diversos projetos em tramitação, verificou-se a omissão de um ou mais dos pilares normativos que se espera da atuação legislativa em matéria de whistleblowers, o que pode dificultar a elaboração de arquiteturas de escolhas que incentivem as pessoas a reportar. Mesmo as inovações inseridas recentemente na Lei no 13.308, de 2018, carecem de um aperfeiçoamento regulamentar que possibilite uma implementação clara e efetiva das garantias que a referida lei almeja conferir ao reportante.

\section{REFERÊNCIAS DAS FONTES CITADAS}

BANISAR, David. Whistleblowing: international standards and developments. Disponível em: <ssrn.com/abstract=1753180>. Acesso em: 20 de janeiro de 2018.

BIT. Corruption: can a behavioural approach shift the dial?, 2016. Disponível em: $<$ www.behaviouralinsights.co.uk/international/corruption-can-a-behaviouralapproach-shift-the-dial/>. Acesso em 06 de novembro de 2017.

BRASIL. Câmara dos Deputado. Projeto de Lei PL no 3.165/2015. Institui o Programa de Incentivo à Revelação de Informações de Interesse Público e dá outras providências.

Disponível

em: $<$ www.camara.gov.br/proposicoesWeb/prop_mostrarintegra?codteor=1393836\&filena $\mathrm{me}=\mathrm{PL}+3165 / 2015>$. Acesso em: 22 de fevereiro de 2018 . 
VARELLA, Marcelo D.; DEMATTÉ, Flávio R.. Limites e possibilidades de melhoria dos programas de whistleblowers para o combate à corrupção no brasil. Revista Eletrônica Direito e Política, Programa de Pós-Graduação Stricto Sensu em Ciência Jurídica da UNIVALI, Itajaí, v.15, n.2, 20 quadrimestre de 2020. Disponível em: www.univali.br/direitoepolitica - ISSN 1980-7791

BUGARIN, Maurício Soares; BUGARIN, Tomás Tenshin Sataka. Ética \& Incentivos: devemos recompensar quem denuncia corrupção? Revista Direito GV, São Paulo, v. 13 , n. 2, p. 390-427, mai-ago 2017.

CONSEIL d'ETAT. Le droit d'alerte: signaler, traiter protéger. Paris: La Documentation Française, 2016.

ENCCLA. Subsídios para implantação de programas de whistleblower no Brasil, 2016. Disponível em: <http://enccla.camara.leg.br/biblioteca/artigos/whistleblower1/subsidios-para-implantacao-de-programas-de-whistleblower-nobrasil/at_download/file>. Acesso em: 23 de fevereiro de 2018.

FELDMAN, Yuval; LOBEL, Orly. The Incentives Matrix: the comparative effectiveness of rewards, liabilities, duties and protections for reporting illegality. Texas Law Review, v. 87, 2010. Disponível em: <ssrn.com/abstract=1415663>. Acesso em: 18 de dezembro de 2017.

G20. Study on whistleblower protection frameworks: compendium of best practices and guiding principles for legislation, 2012. Disponível em: <www.oecd.org/g20/topics/anti-corruption/48972967.pdf>. Acesso em: 06 de novembro de 2017.

HALPERN, David. Inside the Nudge Unit: How small changes can make a big difference. Ebury Publishing. Edição do Kindle. 2016.

IRS. IRS Whistleblower Program - Fiscal Year 2019 - Annual Report to Congress.

Disponível em: <https://www.irs.gov/pub/irs-pdf/p5241.pdf>. Acesso em: 20 de abril de 2020.

KAHNEMAN, Daniel; TWERSKY, Amos. Judgment under uncertainty: heuristics and biases. Science, New Series, v. 185, n. 4157, p. 1124-1131, 1974. Disponível em: <psiexp.ss.uci.edu/research/teaching/Tversky_Kahneman_1974.pdf >. Acesso em: 10 de novembro de 2017.

OCDE. Phase 3 Report on implementing the Anti-Bribery Convention in Brazil, 2014. Disponível em: <www.oecd.org/daf/anti-bribery/Brazil-Phase-3-Report-EN.pdf>. Acesso em: 15 de dezembro de 2017.

. Commiting to effective whistleblower protection. Paris, 2016. Disponível em: <dx.doi.org/10.1787/9789264252639-en>. Acesso em: 05 de janeiro de 2018.

. Behavioural Insights and Public Policy: lessons from around the world. Paris, 2017. Disponível em: <dx.doi.org/10.1787/9789264270480-en>. Acesso em: 02 de agosto de 2017.

ONU. Resource guide on good practices in the protection of reporting persons. Viena, 2015. Disponível em: <www.unodc.org/documents/corruption/Publications/2015/1504741_Person_Guide_eBook.pdf>. Acesso em: 30 de novembro de 2017.

RAMIREZ, Mary Kreiner. Blowing the whistle on whistleblower protection: a tale of reform versus power. University of Cincinnati Law Review, v. 76, n. 1, p. 183-233, 
VARELLA, Marcelo D.; DEMATTÉ, Flávio R.. Limites e possibilidades de melhoria dos programas de whistleblowers para o combate à corrupção no brasil. Revista Eletrônica Direito e Política, Programa de Pós-Graduação Stricto Sensu em Ciência Jurídica da UNIVALI, Itajaí, v.15, n.2, 20 quadrimestre de 2020. Disponível em: www.univali.br/direitoepolitica - ISSN 1980-7791

2007. Disponível em: <ssrn.com/abstract=1077881>. Acesso em: 06 de novembro de 2017.

RANGONE, Nicoletta. A behavioural approach to administrative corruption prevention. 2016. Disponível em: <ssrn.com/abstract=2881878>. Acesso em: 04 de novembro de 2017.

ROCHA, Márcio Antônio. Subsídios ao debate para a implantação dos programas de whistleblower no Brasil. Revista de Doutrina da $4^{a}$ Região, Porto Alegre, n. 75, dez. $2016 . \quad$ Disponível em: <www.revistadoutrina.trf4.jus.br/artigos/edicao075/Marcio_Rocha.html>. Acesso em: 07 de novembro de 2017.

SEC. 2019 Annual Report to Congress on the Dodd-Frank Whistleblower Program. Disponível em: <www.sec.gov/files/sec-2019-annual\%20reportwhistleblower\%20program.pdf>. Acesso em: 20 de abril de 2020.

SENADO NORTE-AMERICANO. Whistleblower Protection Enhancement Act of 2012: report of the Committee on Homeland Security and Governmental Affairs. Disponível em: <fas.org/irp/congress/2012_rpt/wpea.pdf>. Acesso em: 31 de janeiro de 2018.

SIMON, Herbert. Rational choice and the structure of the environment. Psychological Review, $\quad$. 63, p. 129-138, 1956. Disponível em: <http://digitalcollections.library.cmu.edu/awweb/awarchive?type=file\&item =33544> . Acesso em: 10 de novembro de 2017.

SUNSTEIN, Cass R. Empirically Informed Regulation. University of Chicago Law Review, v. 78, p. 1349-1429, 2011. Disponível em: <chicagounbound.uchicago.edu/uclrev/vol78/iss4/4>. Acesso em: 08 de novembro de 2017.

THALER, Richard H.; SUNSTEIN, Cass R. Nudge: o empurrão para a escolha certa. Rio de Janeiro: Elsevier, 2009.

TRANSPARÊNCIA INTERNACIONAL. International principles for whistleblower legislation, $2013 . \quad$ Disponível em: <www.transparency.org/whatwedo/publication/international_principles_for_whistleblo wer_legislation>. Acesso em: 04 de novembro de 2017.

VAUGHN, Robert G. State whistleblower statutes and the future of whistleblower protection. Administrative Law Review, Washington, v. 51, n. 2, p. 581-625, 1999.

Recebido em: 04/05/2020

Aprovado em: 20/07/2020 